Referencia para citar este artículo: Miano, A., \& Heras, A. I. (2018). Niñas y niños toman la palabra: el potencial formativo de la narración. Revista Latinoamericana de Ciencias Sociales, Niñez y Juventud, 16(2), 979-994. doi:https://doi.org/10.11600/1692715x.16222

\title{
Niñas y niños toman la palabra: el potencial formativo de la narración*
}

\author{
Amalia Miano \\ Investigadora Conicet, Argentina. \\ ANA INÉS HERAS \\ Investigadora Conicet, Argentina.
}

\section{Artículo recibido en septiembre 25 de 2017; artículo aceptado en diciembre 11 de 2017 (Eds.)}

- Resumen (analítico): analizamos una experiencia pedagógica centrada en la narración dirigida a niñas y niños en situación de calle en la ciudad de Buenos Aires. Metodológicamente, tomamos como unidad de análisis a las interacciones que tuvieron lugar en esta experiencia para identificar las oportunidades de aprendizaje sobre la narración desde una perspectiva sociolingüistica. Nuestros resultados evidencian que acercar una variedad de recursos permitió a cada uno de los participantes asumir la toma de la palabra y la expresión, así como crear una enunciación colectiva como grupo. Concluimos que experiencias pedagógicas de este tipo ponen de relieve el potencial formativo de la narración y la expresión, permitiendo denunciar formas de vida que se presentan como no dignas de ser vividas según lo identifican las niñas y niños con quienes trabajamos.

Palabras clave: narración, etnografía pedagógica, niños en alto riesgo (Tesauro Europeo de la Educación).

\section{Children find their voice. The educational potential of narration}

- Abstract (analytical): This study analyzes a pedagogical experience in Buenos Aires City developed by a staff team and a group of volunteers that work with homeless children. The goal of the study was to identify learning opportunities obtained through narration from a sociolinguistic perspective, considering multi-mediated interactions as analytical units. Methodologically, the authors examined the availability, access and transposition of different semiotic systems. The outcomes of the research show that facilitating access to a variety of resources enables individual participants to speak up and express themselves and also enables the group to express itself as a collective. The authors conclude that the pedagogical experiences of this kind clearly establish the educational potential of narration and self-expression and facilitate the description of undignified ways of living, as voiced by the homeless children that participated in the study.

Key words: Narration, pedagogical ethnography, children at high risk (European Education Thesaurus).

\footnotetext{
Este artículo de investigación científica y tecnológica (del área Ciencias de la Educación; Educación General) sistematiza un espacio pedagógico implementado entre los meses de octubre y diciembre del año 2013 en el marco del proyecto de capacitación titulado «Historias bajo el Gomero. Taller de narración y expresión artística», financiado por la Dirección de Fortalecimiento a Organizaciones de la Sociedad Civil del Gobierno de la Ciudad de Buenos Aires. Este proyecto de capacitación se enmarca a su vez en el Proyecto de Investigación Científico Tecnológica (PICT 0696) «Aprendizaje y creación en proyectos de Autonomía», dirigido por la Dra. Ana Inés Heras (01/01/2010 a 31/12/2013), financiado por la Agencia Nacional de Promoción Científica y Tecnológica.

** Dra. en Ciencias Sociales, Magíster en Antropología Social y Lic. en Ciencias de la Comunicación Universidad de Buenos Aires. Investigadora Asistente del Conicet-Cedesi-Unsam e Incluir. Orcid: 0000-0003-1724-1188. Índice H5: 4. Correo electrónico: mariamaly@hotmail.com

*** Doctora y Magíster en Educación. Universidad de Santa Bárbara. California. Investigadora Independiente del Conicet-Cedesi-Unsam e Incluir. Orcid: 0000-0002-0844-1682. Índice H5: 9. Correo electrónico: herasmonnersans2@gmail.com
} 


\section{Crianças tomam a palavra. $O$ potencial formativo da narração}

- Resumo (analítico): analisamos uma experiência pedagógica centrada na narração, dirigida a crianças em situação de rua na cidade de Buenos Aires. Metodologicamente, tomamos como unidade de análise as interações que tiveram lugar nesta experiência para identificar as oportunidades de aprendizagem sobre a narração desde uma perspectiva sociolingüística. Nossos resultados mostram que abordar uma variedade de recursos permitiu que cada um dos participantes tomasse a palavra e a expressão, bem como crias-se uma enunciação coletiva como um grupo. Concluímos que as experiências pedagógicas deste tipo, destacam o potencial formativo da narração e da expressão, $e$ permitem a denúncia das formas de vida que são apresentadas como não dignas de serem vividas, como identificadas por crianças em situação de rua com quem trabalhamos.

Palavras-chave: narração, etnografia pedagógica, crianças em alto risco (Tesauro Europeu da Educação).

A la memoria de Claudia. Tu luz sigue iluminando en cada hoja del Gomero.

- 1. Introducción. -2. Infancia y situación de calle en ciudad de Buenos Aires. -3. Metodología de generación y análisis de datos. -4. Resultados. -5. Discusión y conclusiones. -Lista de referencias.

\section{Introducción}

El objetivo de este artículo es analizar las oportunidades de aprendizaje (Heras \& Presman, 2008) sobre la narración que se dieron en el marco de una experiencia pedagógica dirigida a niñas y niños en situación de calle de la Ciudad de Buenos Aires. Este análisis resulta relevante en tanto que esta experiencia ha permitido a cada participante del taller tomar la palabra y crear junto con otros una enunciación colectiva, plasmada en un libro de cuentos. Interpretamos que esa enunciación colectiva, que asume a su vez una forma de denuncia de determinadas condiciones de vida, se hizo posible porque el diseño pedagógico del taller tomó como punto de partida acercar a los participantes formas de expresión multimediadas. La noción de potencial formativo nos permite evaluar esta experiencia, ya que implica una situación donde los sujetos se posicionan de formas innovadoras, críticas y, a la vez, propositivas en las circunstancias en que se desenvuelven sus vidas, a través de desarrollar tanto la imaginación como procedimientos de análisis que tomen en cuenta la asociación entre sí de elementos complejos (Bombini, 2002).

Desde el año 2008 nuestro equipo ha trabajado con un grupo de voluntarios que sostienen un comedor a cielo abierto en la Ciudad de Buenos Aires para analizar junto a ellos sus actividades. Previo al momento de servir la comida tiene lugar el apoyo escolar o simplemente «apoyo» (en el lenguaje de los voluntarios), al que asisten alrededor de veinte niñas, niños y adolescentes de entre dos y 12 años. La documentación del apoyo comenzó en el año 2010 y siguió tres ciclos: a) durante 2010-2012, en el contexto de un centro barrial comunitario que prestó sus instalaciones; b) entre enero y agosto de 2013, bajo el árbol que nuclea el momento de la comida; c) desde octubre a diciembre de 2013, en el cual se implementó el taller «Historias bajo el Gomero». Este trabajo previo nos permitió identificar que la mayor parte de las niñas, niños y adolescentes que asistían al apoyo no conocían las convenciones básicas de la narración (ligadas a identificar una introducción, un nudo y un desenlace). Muchos de ellos incluso no sabían leer y escribir y su contacto con la escolarización formal no era sistemático. Esta situación nos llevó a crear una propuesta pedagógica basada en la lectura de imágenes y en las posibilidades de expresión a través de diversos formatos. Tomamos para ello los aportes de los «nuevos estudios de literacidad» (NEL de aquí en adelante, Barton \& Hamilton, 1998; Gee, 1986; Street, 1984; Zavala, 2002; Zavala, Niño-Murcia, \& Ames, 2004) que parten de 
cuestionar la preponderancia de la escritura como instrumento legítimo de expresión e inscripción de sentidos frente a otras formas de expresión. Los NEL definen a la literacidad como «un conjunto de prácticas discursivas, es decir, como formas de usar la lengua y otorgar sentido tanto en el habla como en la escritura. Estas prácticas discursivas están ligadas a visiones del mundo específicas (creencias y valores) de determinados grupos sociales o culturales» (Gee, 1986, en Zavala et al., 2004, p. 24). Esta definición destaca dos dimensiones relevantes de los procesos de significación a través de la lengua. Por un lado, devela que estos procesos implican una práctica, una puesta en acto de un acontecimiento discursivo en contraposición a considerarlos únicamente como la internalización de una habilidad técnica que lleva a asociar sonidos con significados. Por otro lado, reconoce que esta puesta en práctica de la lengua está impregnada de valores sociales y, por tanto, la situación interactiva en que se desenvuelve cobra importancia para el análisis.

Estas corrientes sirven como referencia al análisis que presentaremos, ya que desarrollan sus estudios tanto en situaciones escolares como comunitarias y barriales donde se identifican procesos de aprendizaje sobre y a través del uso de la lengua en todas sus variantes y posibilidades. De este modo, quienes estudian el desarrollo del lenguaje y de la literacidad desde estas perspectivas, aún cuando lo hacen en contextos escolares, parten de suponer que lo que se aprende no es una mera técnica y un procedimiento de decodificación mecánicos, sino que lo que está en juego es el desarrollo de sentidos producidos a través de la poética verbal que, a su vez, se asienta en una multiplicidad de soportes y formatos (Hymes, 1996).

Los NEL no restringen el concepto de literacidad a la escritura alfabética, sino que consideran que la significación puede realizarse a través de diversos códigos (Scollon \& Scollon, 1981) abarcando así diferentes sistemas semióticos. Esto abre la posibilidad de analizar diversos sistemas como soportes de significación, tal como se estaba formulando con anterioridad desde el campo de la semiótica (Barthes, 1993; Eco, 1972). Específicamente, a partir de la década de 1970, comienza a utilizarse el concepto de «alfabetización visual» para dar cuenta del significado de las imágenes y los objetos (Raney, 1998).

Tomar el concepto de oportunidades de aprendizaje (Heras, \& Presman, 2008) implica partir de la premisa de que en toda situación interactiva se producen dinámicamente significados y contenidos que, potencialmente, permiten desarrollar un conocimiento que antes no se tenía. Se presume así que quienes se encuentran en interacciones de este tipo portan y al mismo tiempo desarrollan nuevos conocimientos junto a otros. Proponemos tomar esta concepción como punto de partida para el análisis preguntándonos, ¿qué oportunidades de aprendizaje acerca de la narración tuvieron lugar en las interacciones realizadas en el marco del taller?

\section{Infancia y situación de calle en ciudad de Buenos Aires}

A lo largo de la historia las formas de percibir la niñez han sufrido transformaciones. Se ha documentado que la infancia, como modo de nombrar un momento donde es posible no tener la obligación de realizar tareas de reproducción de la vida, surge durante el Renacimiento para Occidente (Ariès, 1996; Postman, 1982). Si bien actualmente se toma esta noción como un sentido común social, se observa que niñas, niños y jóvenes de distintas pertenencias étnicas, sociales, culturales y económicas acceden de forma muy diferencial a sus derechos, es decir, a la posibilidad de no tener la responsabilidad de realizar un trabajo, de contar con una vivienda digna, una buena alimentación, un sostenimiento afectivo y acceso a la escolarización.

En la actualidad, de acuerdo con datos proporcionados por la Unesco ${ }^{1}$, aproximadamente 150 millones de niñas y niños se encuentran en situación de calle en el mundo. En cuanto a la ciudad de Buenos Aires, hemos consultado datos demográficos sobre la población en condición de pobreza

1 Disponible en: http://www.unesco.org/new/es/social-and-human-sciences/themes/fight-against-discrimination/education-of-children-in-need/ street-children. 
según las diversas Comunas según datos del 2006. En los mismos se evidencia que existe una gran desigualdad en cuanto a la concentración de la pobreza en la zona sur de la ciudad, específicamente en las Comunas cuatro y ocho con porcentajes que rondan el 27.9 y el $29.3^{2}$ respectivamente. Estos datos son congruentes con los relevados por Lenta (2016), quien coincide en destacar que las Comunas de la zona sur presentan un alto índice de pobreza y que es donde se concentra también la mayor cantidad de niños, niñas y jóvenes en situación de calle.

Coincidente con estos datos que acabamos de citar, de acuerdo con el Informe Preliminar del Primer Censo Popular de Personas en Situación de Calle ${ }^{3}$ realizado en el año 2017 por organizaciones de la sociedad civil junto con dependencias del gobierno de la ciudad, la mitad del total de las personas censadas en situación de calle se ubican en la zona sur de la ciudad. A su vez, del total de personas censadas, el $13.5 \%$ son menores de 18 años.

De acuerdo con Lenta (2016) en el campo de estudios sobre infancia y situación de calle se encuentran distintas formas de conceptualizar este vínculo. Así, la autora da cuenta de un primer momento en el cual se distinguía entre niñas, niños y adolescentes en la calle (que permanecen gran parte del día en la calle, pero mantienen sus vínculos familiares y, generalmente, regresan a un hogar) y de la calle (para referirse a niñas y niños sin hogar y que desarrollan todas sus actividades en la calle). También se ha hecho referencia a niños con experiencia de vida en calle, para dar cuenta de niños que alternan largos periodos de vida en calle con otros en instituciones o en la casa familiar. Finalmente, también se encuentra la denominación niñez en riesgo la cual plantea al niño como un objeto de tutela e intervención (González-Laurino, 2012).

La categoría niñas, niños y adolescentes en situación de calle - que es la que utilizamos en este trabajo- es tomada también por otros autores (Ávila, \& Palleres, 2014; Lenta, 2016; Llobet, 2010). La misma destaca el carácter contingente de esta forma de vida y es usada por varias organizaciones autogestionadas conformadas por personas en situación de calle de la ciudad de Buenos Aires. Esta categoría incluye tanto a aquellas personas que se encuentran efectivamente viviendo en calle (a las que en otros países se refiere como homeless) como a las que están en riesgo de estarlo (porque viven en paradores nocturnos, hogares de tránsito, pensiones u hoteles familiares).

Existen investigaciones en la ciudad de Buenos Aires que han analizado las formas propias de habitar la calle de adultos, jóvenes y niños, ligadas principalmente a la supervivencia (Ávila \& Palleres, 2014; Palleres, 2004), así como otras que han analizado cómo diferentes colectivos autoorganizados proveen sostén a dichos modos de vivir, creando organizaciones flexibles (Reyes, 2017) y produciendo un encuadre teórico-conceptual basado en la apuesta por la vida (Heras \& Pagotto, 2014).

En este estado de situación para la infancia que vive en situaciones complejas es importante tomar en cuenta que la voz infantil produce distintos enunciados en diversos géneros discursivos, que al ser registrados pueden también ser escuchados y compartidos por otros (Sosenski, 2016). Así, las voces infantiles toman el valor de autoría y testimonio. Resulta importante tener esto en cuenta y analizar en detalle de qué manera se gestan estas producciones y cómo construyen una posibilidad de tomar la palabra.

\section{Metodología de generación y análisis de datos}

Las once sesiones que conformaron el taller fueron documentadas a través de diversos soportes: fotografías, registro audiovisual y crónicas narrativas que eran compartidas con los voluntarios. El visionado y la transcripción detallada del registro audiovisual nos ha permitido recuperar en detalle

2 Área estadísticas y censos GCBA: https://www.estadisticaciudad.gob.ar/eyc/?p=24258.

3 Informe del Primer Censo Popular de Personas en Situación de Calle (Informe preliminar publicado en agosto de 2017). http://proyecto7.org/wpcontent/uploads/2017/07/Informe-preliminar-1\%C2\%BA-CPPSC.pdf. 
los significados construidos a través de la interacción, tanto a nivel lingüístico como kinésico. Estos datos han sido volcados a diversas tablas que incorporamos en el apartado de resultados. Por otro lado, el registro audiovisual nos ha permitido realizar también un video que sistematiza la experiencia del taller ${ }^{4}$.

Procedimos metodológicamente a través del análisis de interacciones que tuvieron lugar en el taller. Hemos realizado un análisis diacrónico de los distintos encuentros ya que, siguiendo a Erickson (1992), entendemos que, si bien la interacción se da cara a cara y en un momento específico, quienes interactúan actualizan en ese momento conocimientos y sentidos ocurridos en momentos anteriores o bien en función de proyectar situaciones futuras. El análisis diacrónico de los encuentros nos permitió identificar sucesos comunicativos (Saville-Troike, 2005) que tuvieron lugar en el taller tomando para ello marcadores espaciales, temporales, verbales y gestuales (Green \& Wallat, 1981) que dan lugar a construir la noción de suceso para fines analíticos. Hemos reconstruido los sentidos que se comunican en interacción (Gumperz, 1982) tomando en cuenta que

el sentido de las interacciones no se completa con el significado de las palabras, sino que se construye en la yuxtaposición de las expresiones lingüísticas con otros sistemas semióticos, tales como los gestos, la dirección de la mirada, la orientación corporal, expresiones faciales, los movimientos de todo el cuerpo, la postura, la variación en la entonación y la particular estructuración del contexto de actividad, así como los artefactos involucrados en la actividad. (Menti \& Alam, 2014, pp. 17-18)

Al realizar el primer paso de investigación diacrónica de las sesiones de trabajo con las niñas, niños y adolescentes resultó importante distinguir entre las categorías de disponibilidad y acceso. Siguiendo a Kalman (2004) la disponibilidad denota la presencia física de materiales e infraestructura necesaria en las situaciones de aprendizaje, mientras que el acceso

permite identificar cómo en la interacción entre participantes, en los eventos comunicativos, se despliegan conocimientos, prácticas lectoras y escritoras, conceptualizaciones y usos; abarca dos aspectos fundamentales, las vías de acceso (las relaciones con otros lectores y escritores, con los textos, con el conocimiento de la cultura escrita y los propósitos y consecuencias de su uso) y las modalidades de apropiación (los aspectos específicos de las prácticas de lengua escrita, sus contenidos, formas, convenciones; sus procesos de significación y procedimientos de uso). (Kalman, 2004, p. 26)

También, recurrimos al procedimiento de generar matrices analíticas para analizar las transposiciones que los niños y niñas realizan desde y hacia diversos sistemas semióticos. Por transposición entendemos la transformación de un tipo de lenguaje a otro, por ejemplo, íconos _imágenes visuales - a palabras —enunciados verbales - (Heras \& Miano, 2012). En esas transposiciones se producen modificaciones sucesivas que van dando lugar a creaciones diferentes a lo largo del tiempo (y que podemos analizar a través de los artefactos, es decir, las producciones generadas por los participantes en el taller). Para analizar estas transposiciones seguiremos los trayectos recorridos por Facundo (11 años). El análisis de las transposiciones y modificaciones que realiza Facundo y su aporte a la obra colectiva del grupo nos permitirá dar cuenta de las oportunidades de aprendizaje sobre la narración, la lectura y la escritura.

Así, analizaremos los registros escritos, audiovisuales y fotográficos de los once encuentros que formaron parte del taller y también las producciones realizadas por los participantes (dibujos, cuento, maquetas).

4 Para ver el video completo: https://www.youtube.com/watch?v=2cwlGuZr0bo 


\section{Resultados}

Asistieron al taller 25 niñas, niños y adolescentes. La mayor parte de ellos contaba con un vínculo de larga data con el comedor a cielo abierto. La asistencia semanal de los participantes era fluctuante ya que solo un grupo de ocho niñas y niños participaron de todos los encuentros, mientras que la asistencia de los demás fue dispareja. Esto exigió, desde la propuesta pedagógica, pensar en jornadas que tuviesen en sí mismas un comienzo y un fin, pero que estuviesen a su vez unidas por un objetivo: la narración y creación de un cuento. De esta manera, el taller consistió en una secuencia de actividades a través de las cuales se propuso a los participantes crear una historia a partir de la proyección de imágenes de algunas obras del pintor argentino Xul Solar ${ }^{5}$. Se acompañó a los niños y niñas a recorrerlas con la vista, ya que, desde la propuesta pedagógica, se trabajó inicialmente desde la visualidad definida como el proceso a través del cual vemos, informado situacional, histórica y contextualmente (Rose, 2016).

El eje metodológico que recorrió toda la propuesta se basó en la transposición a diversos soportes de expresión por lo cual, una vez creado el cuento en las primeras tres sesiones, se les acercó en las jornadas posteriores a los participantes otras formas de expresión tales como la teatralización (lo cual implicó adaptar el cuento para poder hacer con él una obra de títeres), la expresión gráfica (a través de la creación de dibujos y maquetas de los personajes y escenas del cuento) y el sonido (a partir de recrear con materiales de reciclaje los sonidos del cuento). Además, en una de las sesiones se visitó el Museo Xul Solar para ver en vivo la obra de este pintor.

En síntesis, y tomando los registros de las jornadas en su totalidad, hemos reconstruido que a lo largo del taller los niños, niñas y adolescentes tuvieron acceso a:

- conocer otras perspectivas a través de la literatura infantil;

- conocer modos de entender y representar el mundo a través de obra plástica;

- identificar, describir y analizar distintas formas de narrar en distintos soportes y formatos;

- aprender la estructura de un relato y transponerlo a distintos soportes de expresión;

- aprender técnicas específicas de pintura (tanto para decodificar obras plásticas como para crear sus propias producciones);

- identificar y caracterizar a los personajes de una historia;

- organizar un evento para mostrar públicamente algunos de los productos realizados en el marco del taller;

- intercambiar con otros (niñas, niños, adolescentes y adultos) sobre las narraciones literarias, la obra plástica y los análisis que de las mismas surgen en interacción.

Cada una de estas acciones propuestas implicó por parte de los participantes una toma de la palabra para interactuar con otros pares, otros contextos y diferentes medios de expresión. A continuación presentamos los resultados de un análisis de sucesos comunicativos a través de los conceptos de disponibilidad y acceso (4.1). Luego, siguiendo las trayectorias de Facundo, daremos cuenta de las transposiciones (4.2), lo cual nos permitirá identificar las oportunidades de aprendizaje que tuvieron lugar a lo largo del taller.

\subsection{Disponibilidad y acceso a situaciones de aprendizaje}

En la siguiente tabla se presenta cómo la coordinadora de la actividad lee un cuento a los participantes a partir de las imágenes que se ven en él (primer encuentro), planteando la posibilidad de visualizar un cuento sin tomar el texto escrito.

5 La propuesta original del taller había sido trabajar con obras del pintor argentino Antonio Berni. En uno de los primeros encuentros de planificación con los voluntarios, una docente de artes plásticas sugirió trabajar con la obra de Xul Solar ya que su estilo surrealista sería más adecuado para fomentar la imaginación de los niños y niñas. 
Tabla 1. Lectura de un cuento en ronda (10 de octubre)

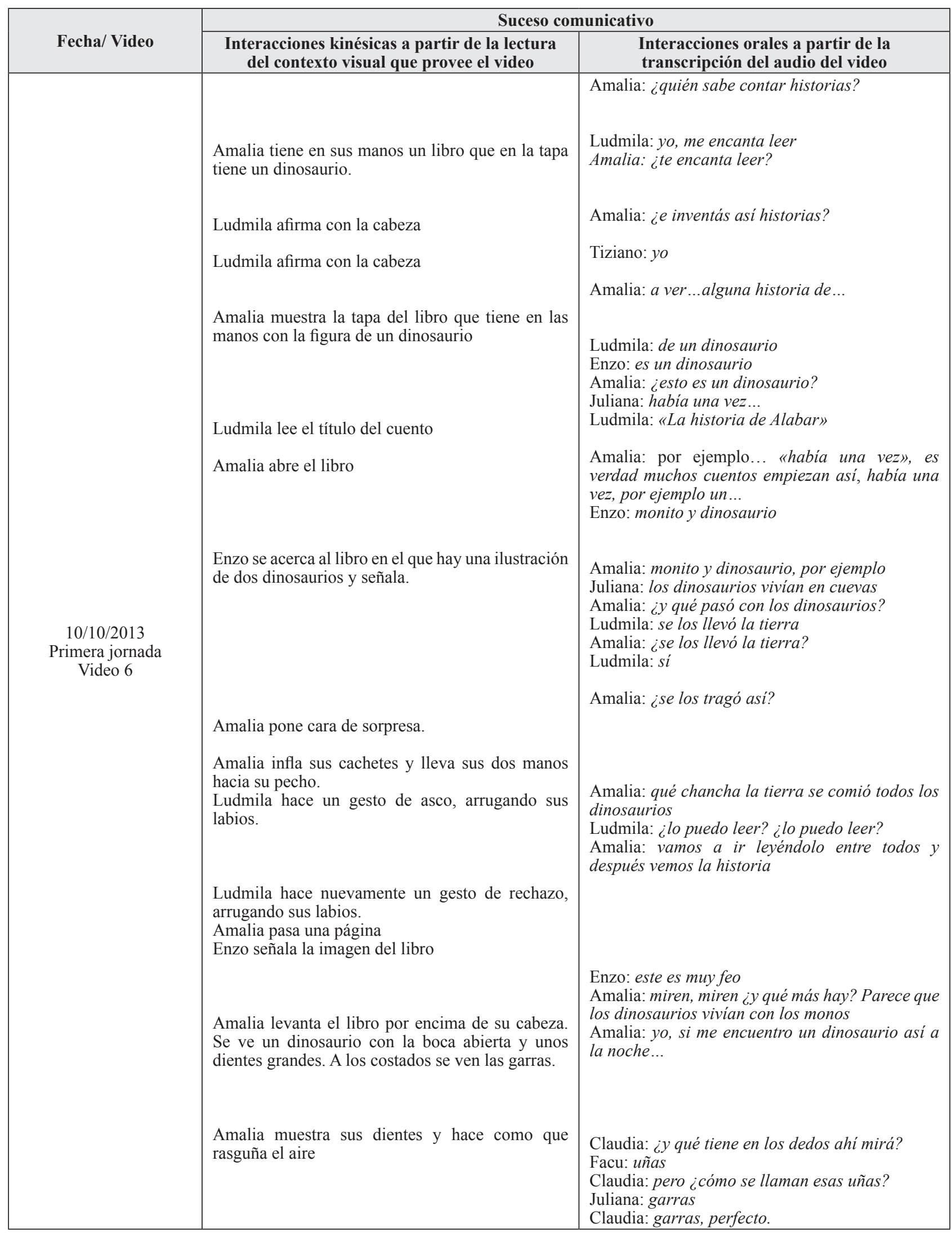


Se disponen al alcance de los niños una serie de recursos (un espacio abierto y una lona para sentarse, linternas, libros de cuentos y adultos que guían las actividades) que a su vez construyen un acceso posible a la narración (leer el libro en ronda y narrar a partir de las ilustraciones).

En este suceso se ponen en juego los siguientes soportes y formatos: lectura del texto por parte de Ludmila (quien quiere incluso leer el cuento a través del texto escrito, pero Amalia le indica que la lectura va a ser a través de las ilustraciones), lectura de las imágenes y lectura de la gestualidad. Así, se construye interactivamente la siguiente información: el libro trata sobre dinosaurios, los dinosaurios vivían junto a los monos y tienen garras en sus patas; además vivían en cuevas. A través de las preguntas que van haciendo Amalia y Claudia se va instalando una forma posible de narrar, diferente a la que hubiera realizado Ludmila, ya que no se realiza la lectura del texto sino una narración desde lo visualizado e interpretado. Se sostiene una pauta discursiva de agregar información (por ejemplo, imaginar que tal vez los dinosaurios desaparecieron porque la tierra se los comió).

Las siguientes fotografías (Serie 1. 10 de octubre, exploración de libros) permiten observar la postura corporal. Las voluntarias proveen con sus cuerpos un resguardo y sostén a través del abrazo, lo cual predispone a la concentración.

Serie 1. 10 de octubre, exploración de libros
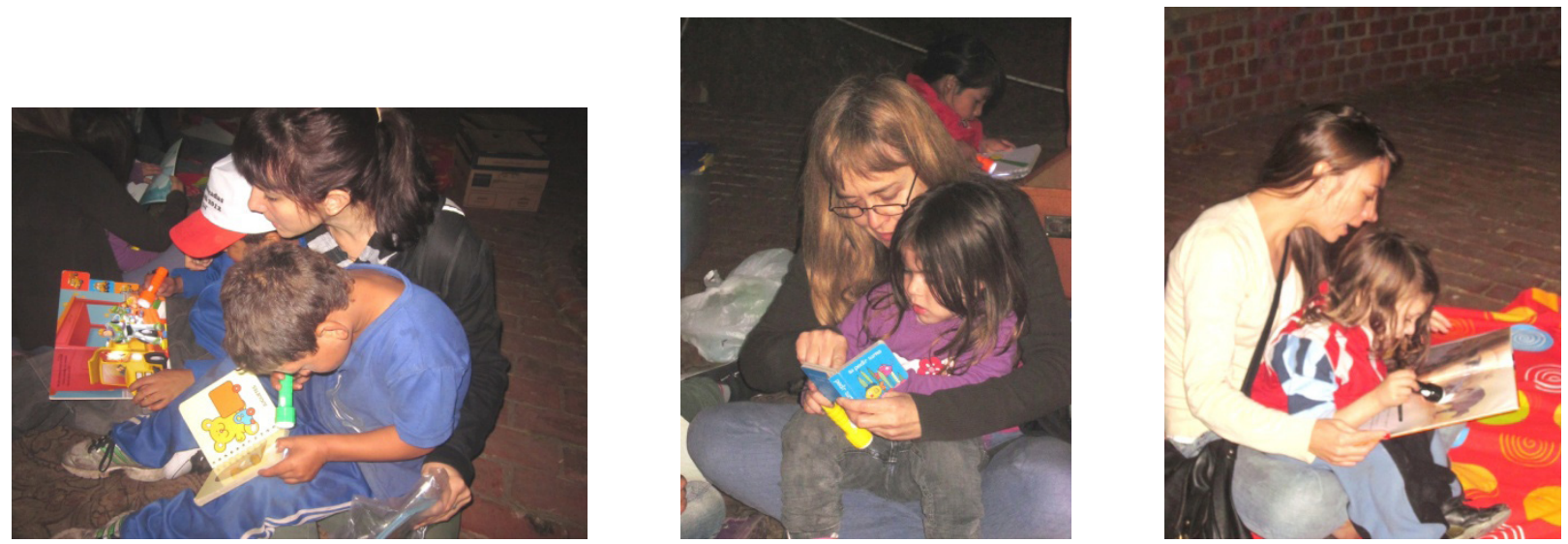

Nota. ․ Teté Di Leo, 2013.

En esta primera jornada, unos minutos después de esta situación, cada uno de los chicos elige y explora un libro junto a una voluntaria. Analizamos a continuación cómo Sofía, ya sin la necesidad de que intervenga la voluntaria, realiza su propia lectura del libro a partir de las ilustraciones a través de la descripción de imágenes y de imaginar relaciones; por ejemplo, un vínculo de noviazgo entre los perros y otro vínculo filial entre los elefantes. Así, adopta la pauta de visualización y narración que se dio en la situación anterior y le cuenta un cuento a otra niña a partir de las ilustraciones. 
Tabla 2. Sofia lee un cuento a Martina (10 de octubre)

\begin{tabular}{|c|c|c|}
\hline Fecha/ Video & $\begin{array}{c}\text { Interacciones kinésicas a partir de la lectura } \\
\text { del contexto visual que provee el video }\end{array}$ & $\begin{array}{l}\text { Interacciones orales a partir de la } \\
\text { transcripción del audio del video }\end{array}$ \\
\hline $\begin{array}{c}10 / 10 / 2013 \\
\text { Primera jornada } \\
\text { Video } 15\end{array}$ & $\begin{array}{l}\text { Laura (voluntaria), Sofía y Martina están sentadas } \\
\text { sobre la lona. } \\
\text { Sofía tiene un librito pequeño en sus manos. Lo } \\
\text { abre } \\
\text { Pasa una hoja. Se ve un dibujo de dos perritos } \\
\text { besándose. } \\
\text { Imagen de un elefante chiquito y otro más grande } \\
\text { por detrás. } \\
\text { Da vuelta la hoja pero el cuento se terminó. }\end{array}$ & $\begin{array}{l}\text { Laura: ¿querés que ella te lea el cuento? Vení } \\
\text { dale, vamos a escuchar que nos va a contar ahora } \\
\text { el cuento ella. } \\
\text { Sofía: Había una vez un perrito con un elefante, } \\
\text { tenía la mamá y el bebé. } \\
\text { La perra y el perro eran novios } \\
\text { Los elefantes son familias. La mamá y el hijo. } \\
\text { Y acá estaban los animales, las tortugas, y acá } \\
\text { vino un perro y los gatos. Estaban jugando a la } \\
\text { pelota y acá... colorín colorado este cuento se ha } \\
\text { terminado. }\end{array}$ \\
\hline
\end{tabular}

Las jornadas siguientes del taller (menos la última que se realizó nuevamente en la plaza) se realizaron en una sala de una institución que prestó sus instalaciones.

A continuación analizaremos otro suceso ocurrido en la quinta jornada en la cual los materiales a disposición de los niños son distintos a los que estaban en la plaza pública. En la Tabla 3 se presenta cómo la coordinadora proporciona nuevamente una pauta para narrar a partir de imágenes; en este caso, las fotografías que habían sido tomadas durante una visita a un museo que se había realizado la jornada anterior.

Tabla 3. Lectura de las fotografías de la visita al museo (7 de noviembre)

\begin{tabular}{|c|c|c|}
\hline Fecha/ Video & $\begin{array}{c}\text { Interacciones kinésicas a partir de la lectura del } \\
\text { contexto visual que provee el video }\end{array}$ & $\begin{array}{l}\text { Interacciones orales a partir de la } \\
\text { transcripción del audio del video }\end{array}$ \\
\hline & $\begin{array}{l}\text { Hay una computadora sobre una mesa enchufada a } \\
\text { un proyector. La luz está apagada. Hay varias niñas } \\
\text { sentadas en sillas al lado de la mesa, también está } \\
\text { Amalia. } \\
\text { Karen levanta la mano }\end{array}$ & $\begin{array}{l}\text { Amalia: bueno ¿empezamos? } \\
\text { Niñas: ¡isí!! } \\
\text { Amalia: ¿cómo están en este día de lluvia? } \\
\text { Bueno ¿quiénes de los que están acá fueron al } \\
\text { museo? }\end{array}$ \\
\hline $\begin{array}{c}7 / 11 / 2013 \\
\text { Quinta jornada } \\
\text { Video } 7\end{array}$ & $\begin{array}{l}\text { Amalia va pasando más fotos y relata lo que se va } \\
\text { viendo en las fotos. }\end{array}$ & $\begin{array}{l}\text { Amalia: ¿solo Karen? Bueno, vamos a ver } \\
\text { algunas de las fotos que sacamos el día que } \\
\text { fuimos al museo, así también los que no pudieron } \\
\text { ir pueden ver lo que hicimos ¿sí? Miren a ver, ¿a } \\
\text { quién conocen? } \\
\text { Ludmila: está Laura } \\
\text { Amalia: Laura, muy bien } \\
\text { Juliana: estabas vos } \\
\text { Amalia: también estoy yo ahi, es verdad ¿quién } \\
\text { más? } \\
\text { (niñas enumeran): estaba Gabi, la mamá de } \\
\text { Tiziano } \\
\text { Amalia: nos juntamos en la plaza, comimos } \\
\text { empanadas, después de postre comimos pasta } \\
\text { frola, que es eso que ven ahí. }\end{array}$ \\
\hline Video 9 & Amalia sigue pasando fotos. & $\begin{array}{l}\text { Amalia: ahi está Luciano, que hoy no vino, está } \\
\text { corriendo con un vaso de Coca } \\
\text { Karen: sí, me lo estaba alcanzando a mi } \\
\text { Amalia: ¿en serio? } \\
\text { Karen: sí, pero me quería pegar } \\
\text { Amalia: ¿te quería pegar? Bueno, ven cómo } \\
\text { cuando vamos viendo las fotos nos vamos } \\
\text { acordando de lo que hicimos ese día. }\end{array}$ \\
\hline Video 11 & Siguen más fotos. Amalia sigue relatando. & $\begin{array}{l}\text { Amalia: y ahi entramos al museo } \\
\text { Karen: había un cartel que decía que no se podia } \\
\text { correr, que no se podía tocar } \\
\text { Amalia: tocar las pinturas }\end{array}$ \\
\hline
\end{tabular}


El acceso ocurre a través de preguntas para identificar a las personas conocidas por los niños. A partir de este primer paso la coordinadora comienza una narración sobre lo que ocurrió apoyándose en las imágenes y la oralidad. Las niñas van reconociendo y comentando lo que ven en las fotografías y, al final, Karen repone información que no se ve en la fotografía, tal como venía haciendo Amalia.

Los resultados presentados en esta sección nos permiten sostener que a través de visualizar se sostiene la posibilidad de narrar. Así mismo, durante estas interacciones se provee a los participantes una serie de claves relativas a las formas canónicas que asume la narración en libros de cuentos. A través del análisis de las pautas de interacción (orales, kinésicas y proxémicas, gestuales y de la mirada) damos cuenta de cómo los participantes van construyendo un repertorio de saberes sobre lectura de imágenes y narración.

\subsection{Transposiciones: un análisis diacrónico}

Facundo tiene 11 años. A través de diversas interacciones realizadas en el marco del taller demostró saber leer, escribir, hacer cuentas y conocer todas las tablas de multiplicar. Durante el transcurso del taller jugó un rol central en crear la narración (tercera jornada), como así también en los dibujos que quedaron en la edición final del libro.

Como veremos en la tabla siguiente, en la primera jornada Facundo interactúa con Claudia (voluntaria) en el momento en que se realiza la lectura en grupos pequeños de diversos cuentos. Claudia tiene en sus manos un libro con pinturas de Xul Solar y, a través de lo que van viendo en el libro, Claudia le proporciona a Facundo algunas pautas para leer esas pinturas.

Consideramos que esta interacción entre Claudia y Facundo va a generar un marco de sentido que será re-actualizado y transpuesto en sucesivas jornadas del taller. De esta manera, en la siguiente jornada a la que asistió Facundo (tercera jornada) en la cual se creó el relato del cuento a partir de la proyección de imágenes de pinturas de Xul Solar ${ }^{6}$, podemos identificar en el relato creado por los chicos, la presencia de varios elementos que fueron mencionados en la interacción que tuvo con Claudia durante la primera jornada (el cielo, los hombres con alas de cartón, las escaleras, el agua, el mar).

Habían pasado 15 días entre la primera jornada y la tercera, en la cual se crea el relato. Sin embargo, Facundo recordó la lectura que había realizado de las imágenes de Xul Solar y, al volver a ver esas imágenes proyectadas, integró elementos que habían sido resaltados como constantes de la obra del autor al relato del cuento.

Si analizamos los dibujos y las maquetas que realizó Facundo en la sexta jornada, podemos advertir una vez más la presencia de los mismos elementos. Aun cuando ya había pasado más de un mes de la interacción inicial con Claudia y 15 días desde que se habían proyectado las imágenes, Facundo recreó en sus dibujos y maquetas los mismos elementos: el agua, las escaleras, el cielo y el sol en la figura 4. También, ese día realizó una maqueta (Fotografía 1) en la cual hizo una construcción en elevación con diferentes cajitas de cartón y con banderitas. Podemos interpretar que esta construcción es una transposición del dibujo realizado (figura 1) que, a su vez, reproduce un cuadro de Xul Solar proyectado en la jornada del 24 de octubre. En este cuadro pueden verse casas de colores que se encuentran en altura sostenidos por unos pilotes y escaleras. Las casas se encuentran sobre el agua y están unidas entre ellas por unos cordeles de los cuelgan banderas. Si bien a la maqueta fotografiada le falta el color, podemos observar las banderas que aparecen en el cuadro y la idea de una construcción de torres rectangulares sostenida por pilotes y conectadas entre sí.

$6 \quad$ Pueden observarse algunas obras de este pintor en: www.xulsolar.org.ar 
Tabla 4. Interacción entre Facundo y Claudia (10 de octubre)

\begin{tabular}{|c|c|c|}
\hline Fecha/video & $\begin{array}{l}\text { Interacciones kinésicas a partir de la lectura } \\
\text { del contexto visual que provee el video }\end{array}$ & $\begin{array}{l}\text { Interacciones orales a partir de la } \\
\text { transcripción del audio del video }\end{array}$ \\
\hline $\begin{array}{c}\text { 10/10/2013 Primera } \\
\text { jornada } \\
\text { Video } 15\end{array}$ & $\begin{array}{l}\text { Claudia tiene en sus manos un librito que lleva } \\
\text { como título «El mago Xul». A su lado está sentado } \\
\text { Facundo con una linterna en la mano. } \\
\text { Claudia lee el libro. } \\
\text { Claudia termina de leer. } \\
\text { Facu acerca la linterna al libro y señala lo que ve } \\
\text { con la linterna. }\end{array}$ & 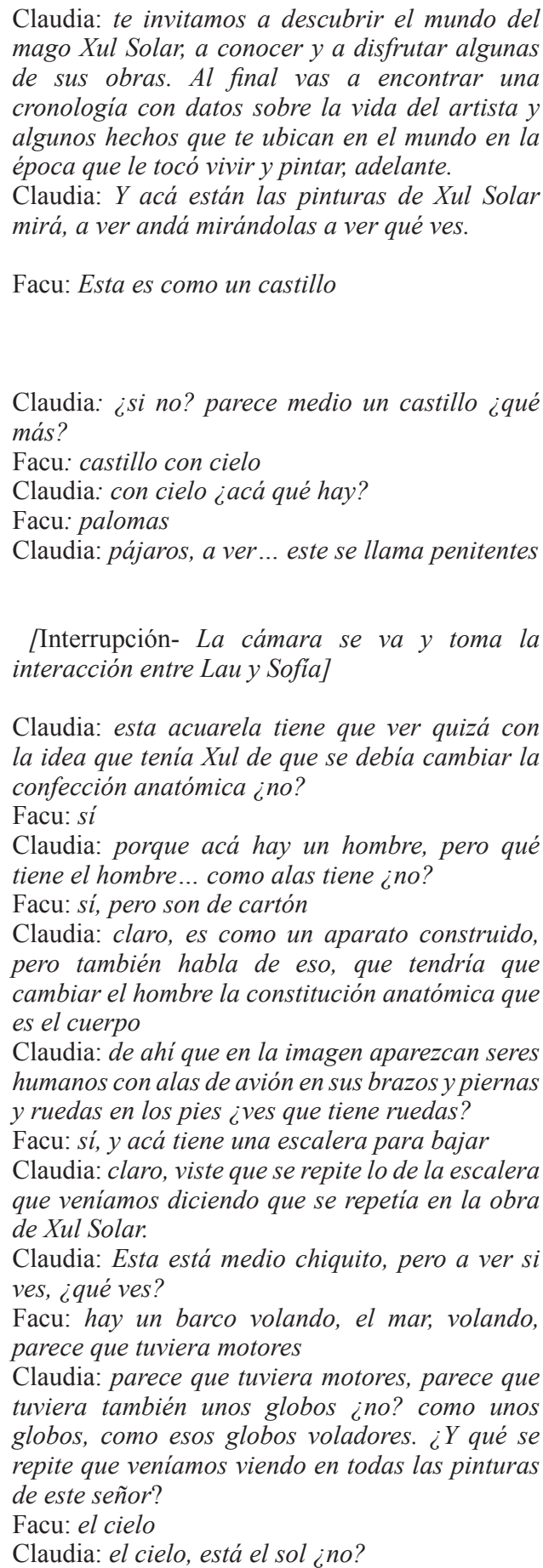 \\
\hline
\end{tabular}


Figura 1. Dibujo realizado por Facundo

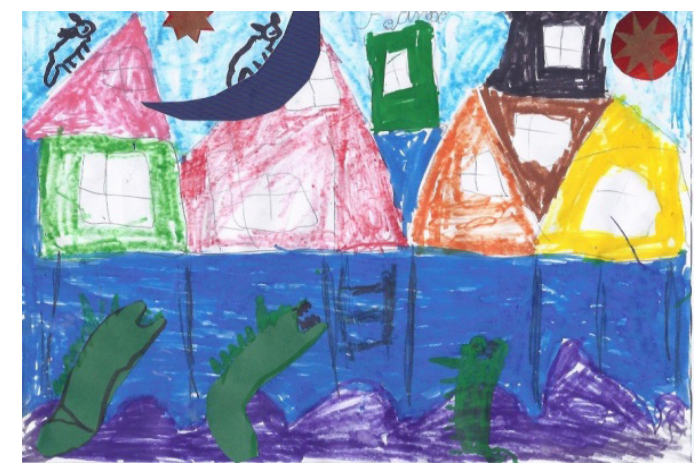

Fotografía 1. Maqueta

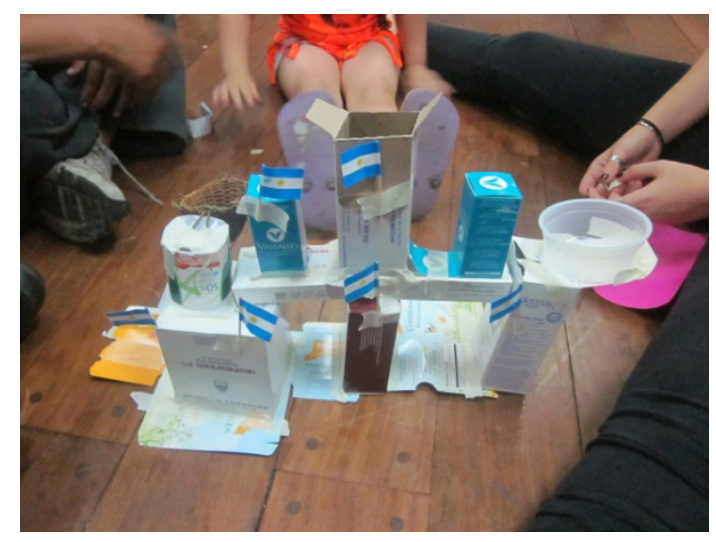

Nota. ․ Teté Di Leo, 2013.

La Tabla 5 nos permite ver las sucesivas transposiciones y modificaciones realizadas por Facundo en el transcurso del taller.

Tabla 5. Transposiciones realizadas por Facundo

\begin{tabular}{|c|c|c|c|c|}
\hline $\begin{array}{c}\text { Primera jornada } \\
10-10-2013 \\
\end{array}$ & $\begin{array}{c}\text { Tercera Jornada } \\
\mathbf{2 4 - 1 0 - 2 0 1 3} \\
\end{array}$ & $\begin{array}{c}\text { Tercera Jornada } \\
\mathbf{2 4 - 1 0 - 2 0 1 3} \\
\end{array}$ & $\begin{array}{c}\text { Sexta jornada } \\
14-11-2013\end{array}$ & $\begin{array}{c}\text { Sexta jornada } \\
14-11-2013 \\
\end{array}$ \\
\hline $\begin{array}{l}\text { Interacción con } \\
\text { Claudia. Pautas de } \\
\text { lectura de la obra de } \\
\text { Xul Solar. Recor- } \\
\text { rido de elementos } \\
\text { que aparecen de } \\
\text { forma recurrente en } \\
\text { la obra del pintor. }\end{array}$ & $\begin{array}{l}\begin{array}{l}\text { Proyección de imá- } \\
\text { genes. }\end{array} \\
\text { Cuadro "Proyecto } \\
\text { fachada Delta 2". } \\
\text { Disponible en: } \\
\text { https://www.wiki- } \\
\text { art.org/en/xul-solar/ } \\
\text { proyecto-fachada-del- } \\
\text { ta-2-1954 }\end{array}$ & $\begin{array}{l}\text { Creación del relato: } \\
\text { Hay muchas casas } \\
\text { que tienen cuadra- } \\
\text { dos en las venta- } \\
\text { nas, también es- } \\
\text { caleras y son altas } \\
\text { porque están sobre } \\
\text { el agua. }\end{array}$ & $\begin{array}{l}\text { Realización de los } \\
\text { dibujos para el cuento. }\end{array}$ & Creación de maquetas. \\
\hline
\end{tabular}


Señalamos que la voluntaria que escribió el relato final a partir de lo que iban diciendo los chicos fue Claudia, por lo cual consideramos que la puesta en sentido realizada conjuntamente entre Facundo y Claudia fue retomada tanto por el niño como por la voluntaria como marco de referencia en las sesiones sucesivas.

La trayectoria de la transposición en el análisis que hemos realizado es la siguiente: de las imágenes a un relato oral (en el caso de la primera jornada en la cual se comentan las imágenes del libro); nuevamente desde las imágenes a un relato oral que luego se transpone a un lenguaje escrito (transposición realizada por Claudia en la tercera jornada en la cual se crea el cuento). Finalmente, en la sexta jornada, transposición desde la oralidad (lectura del cuento para que todos los participantes recuerden la historia) hacia las imágenes (dibujos y maquetas).

Como fuimos mostrando, al transponer se producen modificaciones y creaciones, al mismo tiempo que podemos identificar que algunos elementos ligados a la imagen permanecieron de forma invariable (elementos recurrentes de la obra de Xul Solar). Nos interesa destacar que las claves de lectura aportadas por Claudia durante la primera jornada crearon un marco de significación para Facundo quien pudo plasmar y transponer esas claves en distintos soportes semióticos (oralidad que luego se convierte en palabra escrita, dibujos y maquetas). Así, Facundo fue navegando y explorando diversas formas de significación a partir de un mismo relato.

\section{Discusión y conclusiones}

A través del análisis de distintos sucesos comunicativos que tuvieron lugar en el taller y de las producciones realizadas por los niños y niñas en el marco del mismo, estamos en condiciones de presentar algunas interpretaciones respecto a las oportunidades de aprendizaje ligadas a la narración a través de incorporar la multi-medialidad.

En primer lugar, interpretamos que la toma de la palabra por parte de las niñas y niños es a la vez una denuncia a la violencia social ejercida sobre ellos y una posibilidad de trascender e imaginar otras vidas posibles. Para el diseño pedagógico del taller partimos de considerar que la narración contiene un potencial formativo (Bombini, 2002), tal como mencionamos más arriba, no solo porque permite recorrer una serie de procedimientos técnicos necesarios para crear una trama, sino también porque, tal como lo postuló Ricoeur (1995), la narración es condición para la conformación de la identidad. Para este autor la trama como «configuración narrativa» permite otorgar a la vida una coherencia sin la cual sería imposible responder a la pregunta ¿quiénes somos? Siguiendo esta pregunta y tomando en cuenta el contenido del cuento ${ }^{7}$, podemos advertir que, a través de su trama, los niños, niñas y adolescentes convertidos en autores resaltan la diferencia entre llevar una vida verdaderamente humana de otra que no lo es. Para ello se narra la historia de dos barrios, uno compuesto por casas de colores que están sobre el agua y el otro por cuatro torres. En cada torre de este segundo barrio vive un personaje diferente (una bruja, una princesa, un príncipe y una reina). En los dos barrios existe algún tipo de amenaza: en el primero hay cocodrilos en el agua que pueden atacar, como así también gatos malvados que, cuando son acariciados por sus dueños, se vuelven buenos. Para las niñas y niños en situación de calle lo se pone en juego en las amenazas es muchas veces la propia vida (Pagotto, 2017), de allí la presencia reiterada de este elemento en el cuento. Esa amenaza se desencadena finalmente cuando la bruja del segundo barrio realiza un hechizo y convierte al primer barrio en «caca de elefante». Aquí la vida se transforma en algo inviable, escatológico. La reina luego salva al barrio de este embrujo e inventa los países, abriendo aquí la posibilidad de un renacer diferente. En estos países a la gente le crecen alas para volar y los niños «volvieron a tener vidas humanas». Podemos interpretar que a través de esta narración los niños nos están diciendo que viven constantemente amenazados, que esas amenazas muchas veces ponen en riesgo sus vidas (convirtiendo todo en desecho) y que hay otras formas de vida posible (donde se puede «evolucionar», tener alas para

7 Se puede acceder al libro completo en: https://www.aacademica.org/amalia.miano/54 
volar e inventar todo desde el origen, tal como lo postula la idea de la creación de los países) que son verdaderamente humanas. El potencial formativo de la narración permitió a los niños posicionarse de forma crítica y a la vez propositiva (de otras formas posibles de vida) a partir del reconocimiento de sus actuales condiciones de vida.

En segundo lugar, sostenemos que al acercar a los participantes a distintos soportes de expresión (principalmente obra pictórica) y a distintos contextos (juegos en la plaza, visitas a museos, interacción con otros adultos que les acercan otras formas de expresión), se habilitó la creación de una comunidad de enunciación. Dejamos planteado el lugar del uso del cuerpo (por parte de todos los involucrados) en la posibilidad de construir narración, ya que a través de las corporalidades que contienen y dan afecto, se crea una situación en la que se puede denunciar una forma de vida y proponer otras. Algunas de las características de los sucesos comunicativos analizados han sido reportados por la literatura. Por ejemplo, Cazden (1979) y Ninio y Bruner (1978) identifican la alternancia de turnos en la lectura en la cual las madres dirigen la atención hacia el libro y les hacen a los niños preguntas sobre lo que ven en él. De esta manera, se construye un diálogo de andamiaje (Cazden, 1979). En el caso del taller, las voluntarias hacen el papel de madres que transmiten maneras de relacionarse y entender los libros y, tal como vimos, esto sucede no solamente a través de las pautas dialógicas sino también a través del uso del cuerpo como lugar simbólico y real de contención afectiva. Específicamente en el ámbito de la salud mental dirigida a niños, niñas y adolescentes, algunos autores (Bunge, Maglio, Carrea, \& Entenberg, 2016; Mesa \& Gómez, 2010) han identificado la importancia que tiene para los niños estrechar vínculos afectivos, sentirse escuchados, ayudados y contenidos por los adultos para su desarrollo integral.

En tercer lugar, y en cuanto a la metodología de análisis, estamos en condiciones de afirmar la fertilidad de tomar las categorías de disponibilidad y acceso para hacer visibles las oportunidades de aprendizaje que se presentan a través del tiempo, cuestión que se hace posible por la metodología de análisis tanto diacrónico como sincrónico. Al poder comprender los sucesos comunicativos desde esta perspectiva, pudimos detallar que la disponibilidad de una serie de materiales (libros, linternas, sala con equipamiento para la proyección de imágenes, artículos para pintar y dibujar, materiales para reciclar, instrumentos, títeres) habilitan canales de expresión que a su vez fueron sostenidos en la interacción con personas con distintos conocimientos específicos (docentes del área de plástica, coordinadores de actividades, titiriteros profesionales, músicos, realizadores audiovisuales) que transmitieron en cada actividad un conjunto de prácticas y modos de relacionarse con los materiales y los libros, y de relacionarse entre los participantes para hacer efectivo el acceso. De esta manera, siguiendo el aporte de los NEL, la lectura se realiza siempre de forma contextualizada y tiene que ver con prácticas discursivas construidas con otros. Fue en el marco de las interacciones entre voluntarios y coordinadores de cada jornada, que se transmitió a los participantes un dispositivo pedagógico para la lectura, la escritura y la narración. Hemos podido mostrar también que si bien la disponibilidad es fundamental, esta se convierte en oportunidad de aprendizaje cuando de alguna manera se ordena el acceso, situación que se produce en interacción con las voluntarias y coordinadores de las actividades.

Al analizar procesos individuales dentro del grupo, el análisis diacrónico de las transposiciones realizadas por Facundo nos permite dar cuenta de las habilidades puestas en juego para leer imágenes, describirlas, recordarlas frente al paso del tiempo, recrearlas, transformarlas en relato oral y reconstruirlas incluso en formatos tridimensionales (en el caso de las maquetas y esculturas realizadas). En estos sentidos, corroboramos lo que los NEL han estado identificando con respecto a la variedad de canales de expresión en la construcción de la literacidad. La potencialidad de incorporar imágenes y de leerlas para inscribir sentidos, apoyándose en la oralidad, la gestualidad, la onomatopeya y otros procedimientos fónico-kinésicos, se tornó evidente a través de nuestro análisis porque en el plano metodológico hemos combinado: 1) un enfoque etnográfico (que se asienta sobre la premisa de volver extraordinario lo que a primera vista parece cotidiano y también exige una estancia prolongada con los grupos con los cuales se realiza la etnografía); 2) el registro audiovisual de las interacciones que permite luego reconstruir de manera detallada información oral, visual y 
contextual; 3) materiales que usualmente no son incorporados en los análisis como lo son las propias producciones de los niños (dibujos, cuento, maquetas) y las imágenes y fotografías proyectadas en el taller. Esta combinación nos permitió contar con registros detallados de situaciones de aprendizaje en las que los niños crean, se expresan, interactúan y se vinculan con los demás, situaciones que desde otros enfoques metodológicos tal vez no hubiesen sido siquiera advertidas.

Por último, destacamos el potencial formativo de la narración para dar la posibilidad a niñas, niños y adolescentes que se encuentran en situaciones de vida compleja de tomar la palabra para expresar, a través del plano de la imaginación, la forma en que perciben sus vidas. Quedará en los adultos la responsabilidad de detenerse en esos mensajes, compartirlos y, por supuesto, crear las posibilidades de infancias dignas de ser vividas.

\section{Listado de referencias}

Ariès, Ph. (1996). Ensayos de la memoria. 1943-1983. Buenos Aires: Norma.

Ávila, H., \& Palleres, G. (2014). La calle no es un lugar para vivir: auto-organización y situación de calle en ciudad de Buenos Aires. Buenos Aires: Proyecto 7.

Barthes, R. (1993). Elementos de semiología y El mensaje publicitario. En R. Barthes. La aventura semiológica (pp. 17-84 y 239-244). Barcelona: Paidós.

Barton, D., \& Hamilton, M. (1998). Local literacies: Reading and writing in one community. Londres: Routledge.

Bombini, G. (2002). La literatura en la escuela. En M. Alvarado (Coord.), Entre líneas: teorías y enfoques en la enseñanza de la escritura, la gramática y la literatura, (pp. 53-4). Buenos Aires: Flacso, Manantial.

Bunge, E., Maglio, A., Carrea, G., \& Entenberg, G. (2016). Satisfacción y tipo de servicios de salud mental para niños y adolescentes. Revista Latinoamericana de Ciencias Sociales, Niñez y Juventud, 14(1), 401-415. doi:10.11600/1692715x.14127250615

Cazden, C. B. (1979). Peekaboo as an instructional model: Discourse development at home and at school. Papers and Reports in Child Language Development, (17), 1- 29.

Eco, U. (1972). Tratado de semiótica general. Barcelona: Lumen.

Erickson, F. (1992). Ethnographic microanalysis of interaction. En M. Le Compte, W. Millroy, \& J. Preissle (Eds.), The handbook of qualitative research in education (pp. 210-225). San Diego: Academic Press.

Gee. P. (1986). Oralidad y literacidad: del pensamiento salvaje a ways with words. En V. Zavala, M. Niño-Murcia, \& P. Ames (Eds.), Escritura y sociedad: nuevas perspectivas teóricas y etnográficas (pp. 23-55). Lima: Red para el Desarrollo de las Ciencias Sociales del Perú.

González-Laurino, C. (2012). Usos y consecuencias de las ideas de riesgo y vulnerabilidad social en el peritaje socio-psicológico. Revista Latinoamericana de Ciencias Sociales, Niñez y Juventud, 10(2), 927-941.

Green, J. L., \& Wallat, C. (1981). Mapping instructional conversations: A sociolinguistic ethnography. En J. Green \& C. Wallat (Eds.), Ethnography and language in educational settings (pp. 161205). Norwood: Ablex.

Gumperz, J. (1982). Discourse strategies. Nueva York: Cambridge University Press.

Heras, A. I., \& Miano, A. (2012). El lenguaje audiovisual en la investigación social y la comunicación pública del conocimiento. Revista Ciencia, Público y Sociedad, (1), 18-40.

Heras, A. I., \& Pagotto, A. (2014). Enfoques y sus traducciones a prácticas organizacionales: instituyendo la noción del derecho a sostener la vida. Ponencia presentada en IV Jornadas Psicología Institucional, La Plata, Argentina.

Heras, A. I., \& Presman, B. (2008). Género, (des)igualdad y desarrollo: un análisis de situaciones de aprendizaje en contextos escolarizados. Revista Aportes, (25), 137-158. 
Hymes, D. (1996). Ethnography, linguistics, narrative inequality: Toward an understanding of voice. Bristol: Taylor and Francis.

Kalman, J. (2004). Saber lo que es la letra. México, D. F.: Siglo XXI.

Lenta, M. (2016). Niños, niñas y adolescentes en situación de calle. Buenos Aires: Eudeba.

Llobet, V. (2010). ¿Fábrica de niños?: las instituciones en la era de los derechos de la infancia. Buenos Aires: Noveduc.

Menti, A. B., \& Alam, F. (2014). Los gestos y la enseñanza de palabras poco familiares: ¿cuándo emplean las maestras información gestual? Bellaterra Journal of Teaching and Learning Language \& Literature, 7(1), 17-32.

Mesa, A. M., \& Gómez, A. C. (2010). La mentalización como estrategia para promover la salud mental en bebés prematuros. Revista Latinoamericana de Ciencias Sociales, Niñez y Juventud, $8(2), 835-848$.

Ninio, A., \& Bruner, J. (1978). The achievement and antecedents of labelling. Journal of Child Language, (5), 1-15.

Pagotto, A. (2017). El devenir animal y la morada desde la noción de frontera: narraciones literarias y producciones estéticas de niños y niñas de vida errante. Ponencia presentada en II Congreso Latinoamericano de Teoría Social, Buenos Aires, Argentina.

Palleres, G. (2004). Conjugando el presente: personas sin hogar en la ciudad de Buenos Aires. Buenos Aires: Sociedad Argentina de Antropología.

Postman, N. (1982). The disappearance of childhood. Nueva York: Vintage Books.

Raney, K. (1998). A matter of survival: On being visually literate. The English and Media Magazine, (39), 37-42.

Reyes, S. (2017). La escuela Isauro Arancibia: una experiencia colectiva de educación popular en el sistema formal. Buenos Aires: Noveduc.

Ricoeur, P. (1995). Tiempo y narración, III. México, D. F.: Siglo XXI.

Rose, G. (2016). Visual methodologies: An introduction to researching with visual materials. Thousand Oaks: Sage.

Saville-Troike, M. (2005). Etnografía de la comunicación. Buenos Aires: Prometeo, Untref.

Scollon, R., \& Scollon, S. B. K. (1981). Narrative, literacy and face in interethnic communication. Norwood: Ablex.

Sosenski,S.(2016). Darcasa a las voces infantiles, reflexiones desdelahistoria. Revista Latinoamericana de Ciencias Sociales, Niñez y Juventud, 14(1), 43-52. doi: 0.11600/1692715x.1411250315

Street, B. V. (1984). Literacy in theory and practice. Cambridge: Cambridge University Press.

Zavala, V. (2002). Desencuentros con la escritura. Lima: Red para el Desarrollo de las Ciencias Sociales del Perú.

Zavala, V., Niño-Murcia, M., \& Ames, P. (2004). Escritura y sociedad: nuevas perspectivas teóricas y etnográficas. Lima: Red para el Desarrollo de las Ciencias Sociales del Perú. 